\title{
Large clinical databases for the study of lung cancer: Making up for the failure of randomized trials
}

\author{
Chi-Fu Jeffrey Yang, MD, ${ }^{a}$ Matthew G. Hartwig, MD, ${ }^{a}$ Thomas A. D’ Amico, MD, ${ }^{a}$ and Mark F. Berry, MD ${ }^{b}$
}

\footnotetext{
From the a Division of Thoracic Surgery, Department of Surgery, Duke University Medical Center, Durham, NC; and the ${ }^{b}$ Department of Cardiothoracic Surgery, Stanford University, Stanford, Calif.

Supported by the NIH-funded Cardiothoracic Surgery Trials Network (to M.G.H.), 5U01HL088953-05, and by the American College of Surgeons Resident Research Scholarship (to C.J.Y.).

Disclosers: T.A.D. serves as a consultant for Scanlan International, Inc. All other authors have nothing additional to disclose with regard to commercial support.

Received for publication Aug 30, 2015; accepted for publication Aug 31, 2015; available ahead of print Sept 29, 2015.

Address for reprints: Thomas A. D’Amico, MD, Gary Hock Endowed Professor of Surgery, Section of General Thoracic Surgery, Duke University Medical Center, DUMC Box 3496, Duke South, White Zone, Room 3589, Durham, NC 27710 (E-mail: thomas.damico@duke.edu).

J Thorac Cardiovasc Surg 2016;151:626-8

$0022-5223 / \$ 36.00$

Copyright $@ 2016$ by The American Association for Thoracic Surgery

http://dx.doi.org/10.1016/j.jtcvs.2015.08.110
}

Although randomized controlled trials (RCTs) represent the optimal study design for assessing the efficacy of clinical interventions, the practice of thoracic surgery has historically been significantly influenced by case series and singleinstitution observational cohort studies ${ }^{1}$ because of the well-described difficulties of performing RCTs. ${ }^{2} \mathrm{Re}-$ searchers in the United States and Europe are increasingly using large-scale, population-based administrative databases $^{3-5}$ and clinical registries ${ }^{6-10}$ to perform retrospective cohort studies to answer questions regarding the efficacy, cost, and complications of interventions, to study quality improvement, to assess the treatment of rare conditions, and to evaluate national practice patterns. These studies can significantly enhance quantitative evidence regarding lung cancer treatment when performed by investigators who have clinical expertise in lung cancer with a thorough understanding of both the advantages and limitations of the database being used, through collaboration with experts in advanced statistical techniques.

\section{ADVANTAGES OF ANALYZING LARGE CLINICAL DATABASES}

Well-performed RCTs that minimize bias in patient selection provide the highest grade evidence to guide clinical practice. Although thoracic surgeons have performed extremely influential RCTs in the past, ${ }^{11}$ many barriers to the use of RCTs have generally limited their use in the investigation of surgical interventions for lung cancer, including inadequate equipoise among surgeons and patients, complex institutional administrative requirements for RCT approval, difficulty in obtaining adequate funding, and inadequate research infrastructure in many programs. ${ }^{2}$ Moreover, clinical trials involving thoracic surgical patients are commonly terminated early as a result of poor accrual. $^{12-14}$ As a result, most treatment guidelines for

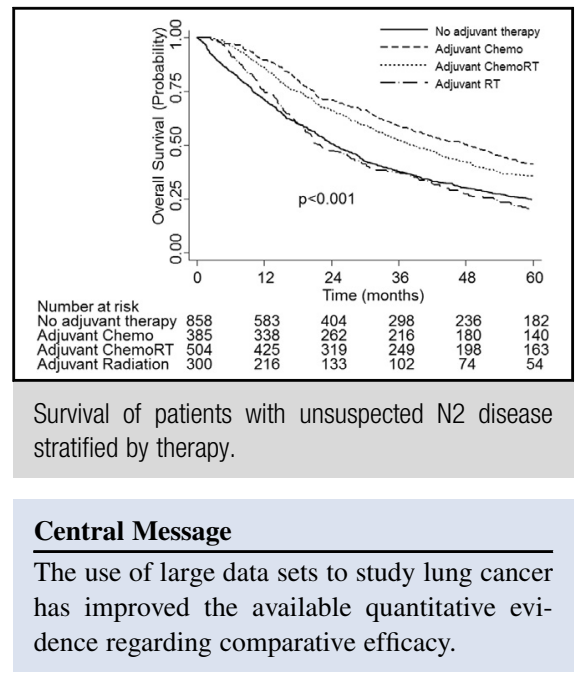

See Articles page 697, 708, and 717, and page 1484, 1496, 1508, and 1517 in the December issue.

See Editorial Commentaries page 706, 715, and 725 .

See Editorial page 1407 in the December issue.

lung cancer surgery are based on experts' interpretations of data from case series and single-institution observational cohort studies. ${ }^{1}$ The evidence from these study designs is more susceptible to bias and carries lower "grades" than that from RCTs.

Well-done studies of large-scale, population-based data sets can bridge the gaps in evidence that result from the dearth of data from RCTs. A major strength of clinical database studies is that their sample sizes are typically orders of magnitude larger than those of randomized, controlled trials and single-institution case series. For example, the National Cancer Data Base (NCDB) receives more than 1 million cancer case reports annually, ${ }^{6}$ and the NCDB contains data on more than 1.5 million patients with non-small cell lung cancer. ${ }^{15}$ The Medicare claims database has data on more than 45 million patients. ${ }^{16}$ The sizes of the available patient populations studied provide unprecedented statistical power to researchers and enable the performance of clinically meaningful subset analyses that would be difficult to do with RCTs. For example, in the Lung Cancer Study 
Group randomized trial of lobectomy versus limited resection for T1 N0 non-small cell lung cancer, investigators had found that limited resection was associated with increased locoregional recurrence for patients with tumors up to $3 \mathrm{~cm}$ in size but were unable to make any conclusions for smaller tumors because of a lack of statistical power. ${ }^{11}$ Two well-designed ongoing randomized trials-the Cancer and Leukemia Group B 140503 and the Japanese Clinical Oncology Group 0802 studies $^{17,18}$ —are focusing on tumors smaller than $2 \mathrm{~cm}$, but they may not have sufficient power to evaluate smaller tumors or compare differences with wedge versus segmentectomy versus lobectomy because of sample size and patient accrual issues. With the statistical power that comes from large clinical data sets, investigators have been able to evaluate the impact of lobectomy versus limited resection on survival for patients with tumors smaller than $2 \mathrm{~cm}^{19,20}$ and smaller than $1 \mathrm{~cm},{ }^{21}$ as well as to evaluate the differences in long-term outcomes with segmentectomy versus lobectomy, ${ }^{22}$ wedge versus segmentectomy, ${ }^{23}$ and wedge versus anatomic resection. ${ }^{24}$

Considering that the highest level of evidence is given when multiple RCTs are available for a clinical situation, studies of large clinical registries or administrative claims databases can perform the important function of confirming results from both RCTs and smaller, single-institution studies. For example, a study of thoracoscopic lobectomy at our institution demonstrated a lower morbidity relative to thoracotomy. ${ }^{25}$ A subsequent national study with the Society of Thoracic Surgeons database found similar results. ${ }^{26}$ Although both studies were propensity-matched analyses, and although the single-institution study was of a prospectively collected database with excellent follow-up, the multi-institutional Society of Thoracic Surgeons database provided a sample size 6 times larger than the singleinstitution study and was far more influential, despite having the limitations of voluntary participation, limited auditing of submitted data, and lack of follow-up beyond 30-days.

In addition, analyses of large-scale data sets have helped provide insight into surgical management topics that can be challenging to study, such as stage IIIA (N2) non-small cell lung cancer treatment. Although a randomized clinical trial provided important data on the role of surgery for N2 disease, the trial's results also raised several questions, ${ }^{27}$ which have yet to be definitively answered with another randomized trial. Population-based data sets allow further investigation into this topic, whereas analysis of single-institution data sets are significantly limited as a result of both institutional biases and small sample sizes associated with the relatively rarity of this disease substage.

Because analyses of large databases are based on data from real-world clinical practice, their results can be more generalizable than specialized single-institution studies or even RCTs, in which the cohorts may be healthier than the typical population of patients with lung cancer. In addition, large clinical databases facilitate development of risk-assessment tools (eg, risk calculators), drive quality improvement and clinical governance, and help facilitate ongoing review of disease incidence, disease mortality, volume-outcome relationships, and national trends in the use of procedures and disparities in health care. ${ }^{28}$ Analyses from large databases can be used to screen various topics related to lung cancer, perhaps to identify which topics would be most appropriate for the investment of resources to conduct a large and expensive RCT.

\section{UNDERSTANDING AND OVERCOMING THE LIMITATIONS OF USING LARGE DATABASES}

All large-scale population-based databases have inherent limitations. Briefly, the Society of Thoracic Surgeons and American College of Surgeons National Surgical Quality Improvement Program databases are clinical registries with detailed comorbidity and postoperative data but are limited in that they only have short-term outcomes. ${ }^{7,9}$ Both the Surveillance, Epidemiology and End Results (SEER) program and NCDB are cancer registries that have longterm survival data but are limited in that they do not have data on recurrence-free survival. ${ }^{6,10}$ Whereas the NCDB includes patient composite comorbidity scores, it does not have detailed comorbidity data, and the Surveillance, Epidemiology and End Results database simply does not have any comorbidity information. ${ }^{6,10}$ The Medicare claims database and Nationwide Inpatient Sample are administrative claims databases that rely on billing codes and as such may suffer from inaccuracies and variabilities in the coding; furthermore, Medicare data do not include patients younger than 65 years. ${ }^{4,5}$ It is critically important that thoracic surgeons with clinical expertise in lung cancer be involved in the design of studies that use these data sets so that the limitations are both minimized and understood and thus results can have meaningful clinical implications. It is also imperative that thoracic surgeons foster collaboration with both biostatisticians and epidemiologists during these studies to achieve the highest possible impact.

\section{CONCLUSIONS}

Analyses of large-scale, multi-institutional data sets are being increasingly performed by researchers to study lung cancer. These studies can provide an important understanding of treatment at a population level and in many situations can enhance quantitative evidence regarding prognosis, efficacy of interventions, and disparities in treatment. Although these studies have limitations and cannot replace the criterion standard of RCTs, appropriate use of these valuable data sets can enhance current evidence and also help direct future research endeavors.

\footnotetext{
References

1. Lee JS, Urschel DM, Urschel JD. Is general thoracic surgical practice evidence based? Annals Thorac Surg. 2000;70:429-31.
} 
2. McCulloch P, Taylor I, Sasako M, Lovett B, Griffin D. Randomised trials in surgery: problems and possible solutions. BMJ. 2002;324:1448-51.

3. Lawson EH, Louie R, Zingmond DS, Brook RH, Hall BL, Han L, et al. A comparison of clinical registry versus administrative claims data for reporting of 30day surgical complications. Ann Surg. 2012;256:973-81.

4. Houchens R, Elixhauser A. 2012 National Inpatient Sample (NIS) Comparison Report. HCUP Methods Series Report \#2015-04. Rockville (MD): US Agency for Healthcare Research and Quality. Available at: http://www.hcup-us.ahrq. gov/reports/methods/methods.jsp. Accessed May 18, 2015.

5. Riley GF. Administrative and claims records as sources of health care cost data. Med Care. 2009;47(7 Suppl 1):S51-5.

6. Bilimoria KY, Stewart AK, Winchester DP, Ko CY. The National Cancer Data Base: a powerful initiative to improve cancer care in the United States. Ann Surg Oncol. 2008;15:683-90.

7. Shahian DM, Jacobs JP, Edwards FH, Brennan JM, Dokholyan RS, Prager RL, et al. The Society of Thoracic Surgeons national database. Heart. 2013;99: 1494-501.

8. Fernandez FG, Falcoz PE, Kozower BD, Salati M, Wright CD, Brunelli A. The Society of Thoracic Surgeons and the European Society of Thoracic Surgeons general thoracic surgery databases: joint standardization of variable definitions and terminology. Ann Thorac Surg. 2015;99:368-76.

9. Khuri SF. The NSQIP: a new frontier in surgery. Surgery. 2005;138:837-43.

10. Yu JB, Gross CP, Wilson LD, Smith BD. NCI SEER public-use data: applications and limitations in oncology research. Oncology (Williston Park). 2009;23:288-95.

11. Ginsberg RJ, Rubinstein LV. Randomized trial of lobectomy versus limited resection for T1 N0 non-small cell lung cancer. Lung Cancer Study Group. Ann Thorac Surg. 1995;60:615-22; discussion 622-13.

12. Schroen AT, Petroni GR, Wang H, Gray R, Wang XF, Cronin W, et al. Preliminary evaluation of factors associated with premature trial closure and feasibility of accrual benchmarks in phase III oncology trials. Clin Trials. 2010;7:312-21.

13. Baggstrom MQ, Waqar SN, Sezhiyan AK, Gilstrap E, Gao F, Morgensztern D, et al. Barriers to enrollment in non-small cell lung cancer therapeutic clinical trials. J Thorac Oncol. 2011;6:98-102.

14. Martins RG, D'Amico TA, Loo BW Jr, Pinder-Schenck M, Borghaei H, Chaft JE, et al. The management of patients with stage IIIA non-small cell lung cancer with N2 mediastinal node involvement. J Natl Compr Canc Netw. 2012;10:599-613.

15. National Cancer Data Base. NCDB public benchmark reports. Cases diagnosed 2003-2013. Available at: http://oliver.facs.org/BMPub/index.cfm. Accessed August 27, 2015

16. Pugely AJ, Martin CT, Harwood J, Ong KL, Bozic KJ, Callaghan JJ. Database and registry research in orthopaedic surgery: part I: claims-based data. J Bone Joint Surg Am. 2015;97:1278-87.
17. Nakamura K, Saji H, Nakajima R, Okada M, Asamura H, Shibata T, et al. A phase III randomized trial of lobectomy versus limited resection for small-sized peripheral non-small cell lung cancer (JCOG0802/WJOG4607L). Jpn J Clin Oncol. 2010;40:271-4.

18. Cancer and Leukemia Group B. CALGB 140503: A phase III randomized trial of lobectomy versus sublobar resection for small $(\leq 2 \mathrm{~cm})$ peripheral non-small cell lung cancer. Available at: http://www.calgb.org/Public/meetings/presentations/ 2007/cra_ws/03-140501-Altorki062007.pdf. Accessed November 22, 2013.

19. Wisnivesky JP, Henschke CI, Swanson S, Yankelevitz DF, Zulueta J, Marcus S, et al. Limited resection for the treatment of patients with stage IA lung cancer. Ann Surg. 2010;251:550-4.

20. Speicher P, Gu L, Gulack BC, Wang X, D'Amico TA, Hartwig MG, et al. Sublobar resection for clinical stage IA non-small cell lung cancer in the United States. Clin Lung Cancer. 2015. In press.

21. Kates M, Swanson S, Wisnivesky JP. Survival following lobectomy and limited resection for the treatment of stage I non-small cell lung cancer $\leq 1 \mathrm{~cm}$ in size: a review of SEER data. Chest. 2011;139:491-6.

22. Whitson BA, Groth SS, Andrade RS, Maddaus MA, Habermann EB, D'Cunha J. Survival after lobectomy versus segmentectomy for stage I nonsmall cell lung cancer: a population-based analysis. Ann Thorac Surg. 2011; 92:1943-50.

23. Yang CJ, Chan DY, Gulack BC, Speicher PJ, Onaitis MW, Tong BC, et al. Wedge resection vs segmentectomy for patients with T1A N0 nonsmall cell lung cancer. In: 16th World Conference on Lung Cancer; 2015 Sep 6-9; Denver.

24. Linden PA, D'Amico TA, Perry Y, Saha-Chaudhuri P, Sheng S, Kim S, et al. Quantifying the safety benefits of wedge resection: a society of thoracic surgery database propensity-matched analysis. Ann Thorac Surg. 2014;98:1705-11; discussion 1711-2.

25. Villamizar NR, Darrabie MD, Burfeind WR, Petersen RP, Onaitis MW, Toloza E, et al. Thoracoscopic lobectomy is associated with lower morbidity compared with thoracotomy. J Thorac Cardiovasc Surg. 2009;138:419-25.

26. Paul S, Altorki NK, Sheng S, Lee PC, Harpole DH, Onaitis MW, et al. Thoracoscopic lobectomy is associated with lower morbidity than open lobectomy: a propensity-matched analysis from the STS database. J Thorac Cardiovasc Surg. 2010;139:366-78.

27. Albain KS, Swann RS, Rusch VW, Turrisi AT III, Shepherd FA, Smith C, et al. Radiotherapy plus chemotherapy with or without surgical resection for stage III non-small-cell lung cancer: a phase III randomised controlled trial. Lancet. 2009; 374:379-86.

28. Saxena A, Newcomb AE, Dhurandhar V, Bannon PG. Application of clinical databases to contemporary cardiac surgery practice: where are we now? Heart Lung Circ. February 19, 2015 [Epub ahead of print]. 